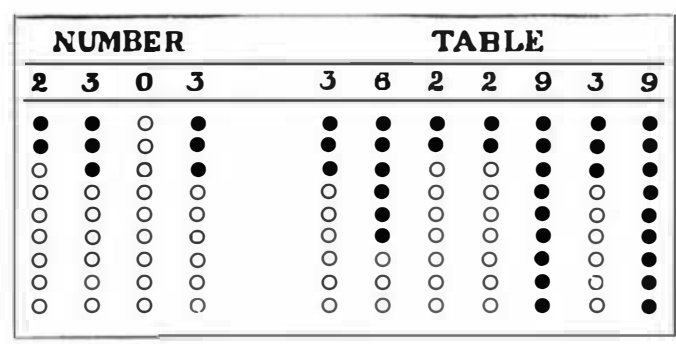

One of the original cards that Babbage used in his "calculating engine"-an invention which was never completed, but which was full of promise.

\title{
Keeping Books by Machine
}

\section{The Punched Card as a Saver of Brain Energy}

By H. S. McCormack

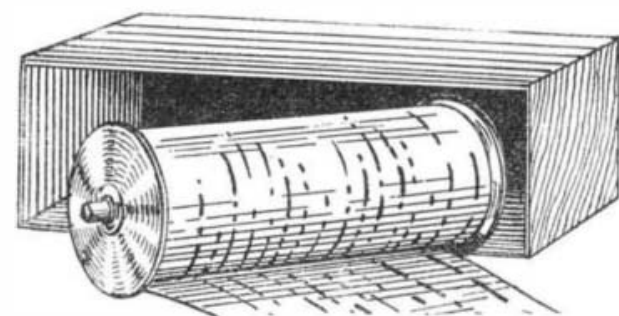

By means of electrical contacts made through holes in thin sheets of brass, the most complicated selections can be artistically rendered upon the piano.
A BOUT a half century ago, an EnglishA man named Babbage started work on an invention which is only now nearin completion. He had studied the operaHon of the Jacquard loom, which through the medium of punched cards weaves de sigas in fabrics. Holes are punched in the cards to form any design reanired-no matter how ornate-and the card in turn causes the loom to produce the pattern in many varieties of textiles.

Babbage figured that if punched cards could build designs in textiles there was no reason why they could not be utilized in the same way to make records.

With thls idea in mind he built a device which he described as a "calculating enche he induced Parliament to approsine." He ind Unfortunately this money was speedily used up in experimental work and $\mathrm{Bab}$ bage got no further than a crude handmade and incomplete model of a device he had in mind. Parliament was skeptical and refused to advance more funds, so Babbage was obliged to cease work and the invention was lost to Engwork
land.

Since Babbage's day the Jacquard principle has been successfully applied to musical instruments, and rolls of punched sheets operate pneumatically the keys of a piano or organ. More recently, through the medium of thin sheets of brass in rolls, an electrical contact is made through the holes, and the most difficult compositions are rendered upon the piano with the crescendo effects and tempo changes of accomplished musician.

How Our Population is Counted and Tabulated With Punched Cards.

Not many years ago the punched card principle wa first applied to statistical work in the United States. Its most prominent use has been in its application to census work. In fact, it has always been called "the census machine" Formerly the tabulation of populaion by States, cities, torns and hamlets; the serresaion of the classes, by native an
The facts embodied in this article uarrant the predictions made by the author and are worthy of serious consideration. Mr. McCormack foresaut present needs by inventing years ago the original typeuriter tabulator. He has studied, advocated and applied efficiency by originating and introducing mechanical inventions into accounting and billing and has proved that his insight into these intricate matters has been based not upon theories but fact. The SCIENTIFIC AMERICAN has arranged for several articles from this author, a recognized authority on eflciency as applied to office and executive management.-EDITOR.

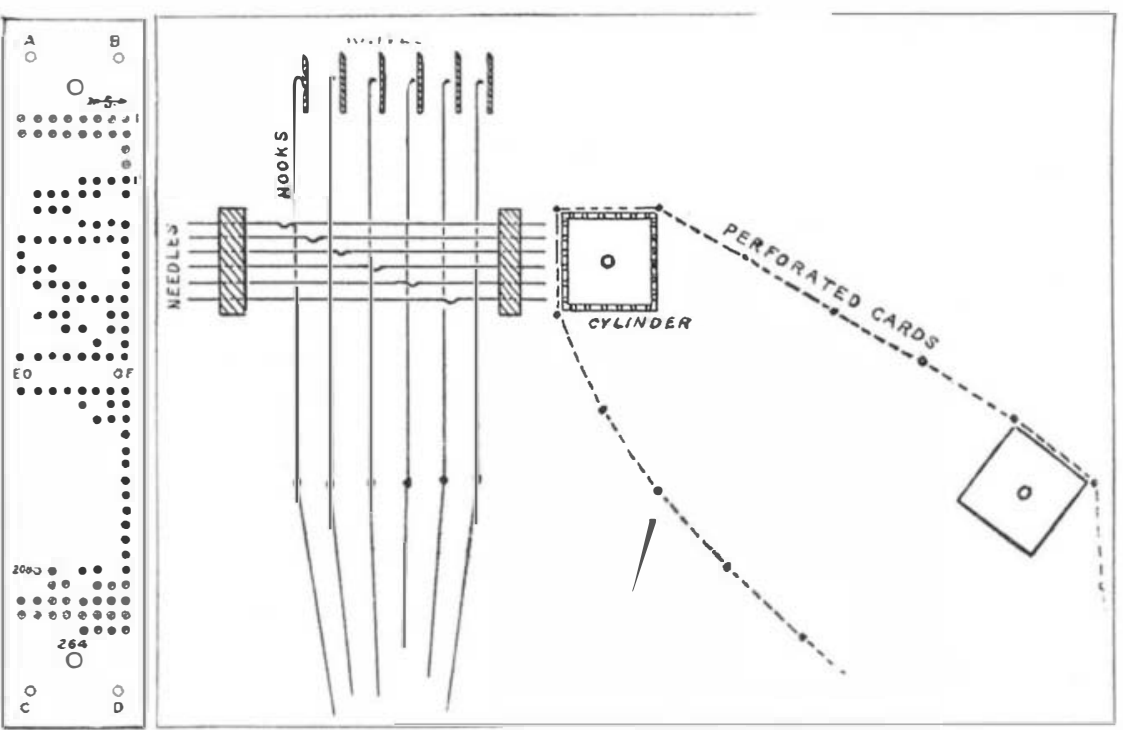

The Jacquard loom, through the medium of punched cards, weaves designs in fabrics. Holes are punched in the cards to form any design required, no matter how ornate, and the card in turn causes the loom to produce the pattern in any varieties of textiles.

and female, white and black, etc., was performed tediously by hundreds of clerks, with the usual percentage of errors and with little opportunity for securing automatic checks, such as are to-day so vital in correct analysis. In addition, it took about ten years to com plete the work. Now it takes ten months.

After the Government found this machine so successful in its work, it was adapted to cost accounting and has been used extensively by large firms. Inventors of business appliances began to see that the punched card principle was capable of infinite adaptation, and could perform operations which were previously considered impossible for a mechanical agency to execute.

An interesting example is the automatic typewriter, which actually takes the place of the human fingers for making duplicate letters.

The Player-piano Principle Applied to the Typewriter.

The writer a few years ago Journeyed to Detroit, Mich., and inspected a hand-made model of an automatic typewriter operator. Here was employed the same principle-punched holes in rolls of paperto turn out form letters actually typewritten. At the time of the examination the hand-made model was a very crude affair of the "soap-box" varlety, but the principle embodied in the model made it a commercial possibility. One of the leading manufacturers bas taken the device under his control, and develope it to a point of practical, usefulnes. It Is almost point of practical usefulness. It is almost impossible to recognize the finished product as an evolution of the crude handmade model produced by the inventors. The device to-day is supplied with a quantity of letterheads and the electrical current turned on; through the application of the pneumatic principle, the machine automatically picks up a letterhead and places it in the carriage the typewrind The letter is space forward to the date line, and the typewriter begins to operate as though actually under the impulse of human hands and fingers. The typewriter carriage moves to the right, and the name, address and salutation are properly placed on the left of the letterhead. Moving from space to space-the keys being depressed and the type bars flying up and down-there is something almost uncanny in the operation of the typewriter as it proceeds step by step to turn out a complete typewritten letter. The completed letter is removed automatically, with no human hands near, and another letter is started. The name, address and salutation are automatically changed and the operation repeated, letter after letter, until the machine automatically stops. Approximately four hundred duplicate business letters a day can be typewritten by this machine.

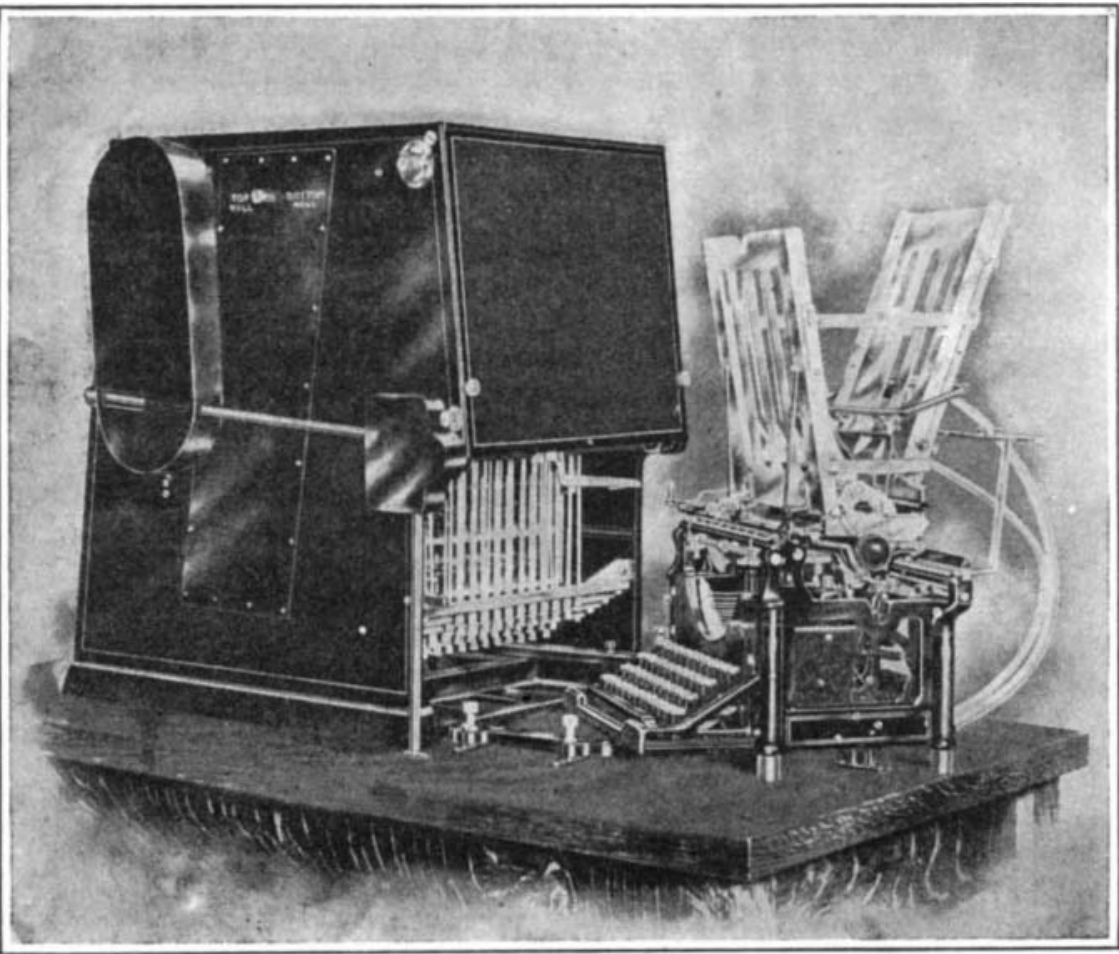

The automatic typewriter takes the place of human fingers. It uses a punched roll of paper like a player-piano. By the application of the pneumatic principle the mechanism operates as though actually under the impulse of human hands and fingers.

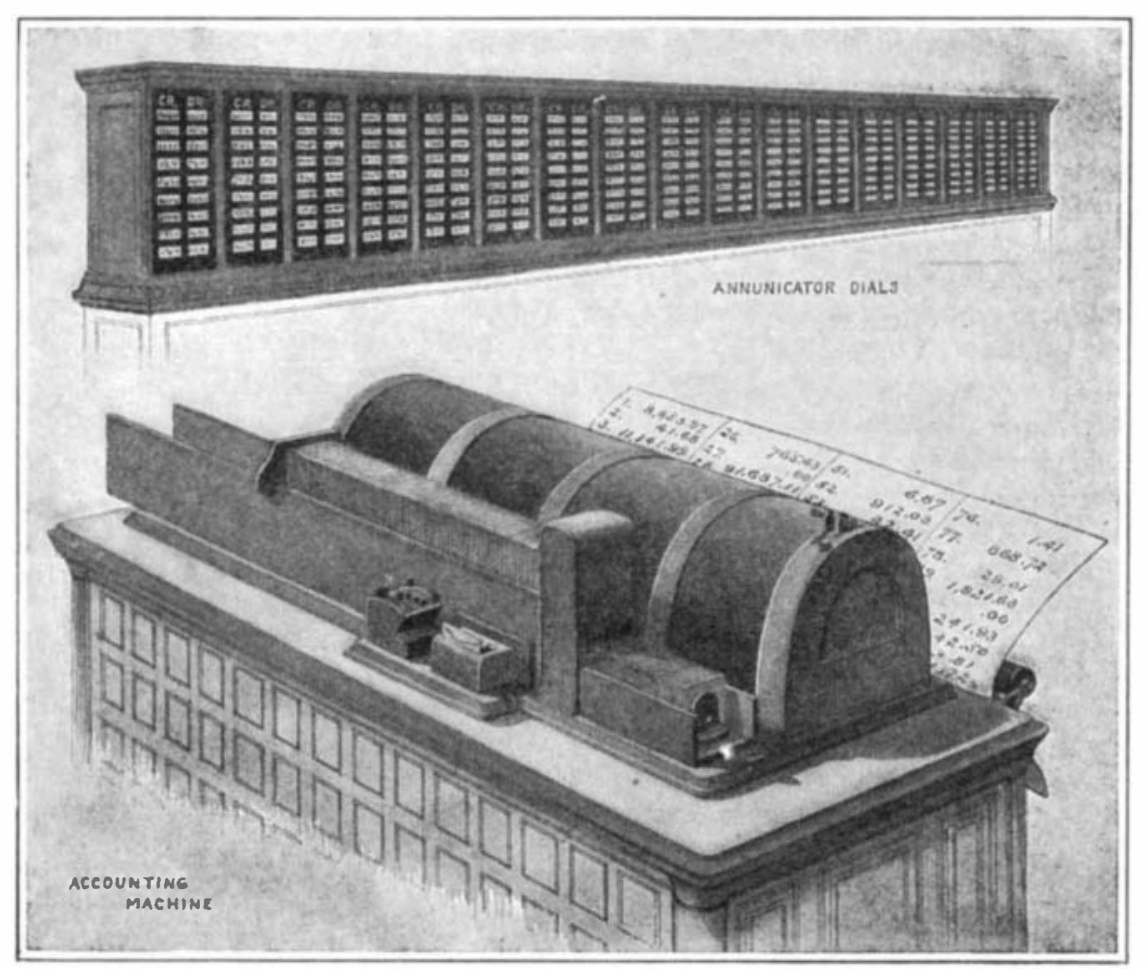

Some day we will have a ledger cabinet, showing debit and credit dials, operated by cards. Clerks will be supplied with cards already punched with thei own number, also the number of their department. When a sale is made they will punch and not write the amount as they do now. 
Now comes what seems the most wonderful application of the punched card principle-that of mechanical bookkeeping and business recording-almost replacing the human brain in its performance, anl indeed out distancing it in accuracy. Through a prealranged plan, four business men recently met: on a railroad official from a distant city, another an official connected with one of the country's leading industrial corporathe country's leading industrial corpora-
tions, the third an official of the greatest tions, the third an official of the greatest president of a concern of interliational reputation.

These men were brought together for the purpose of considering at a private demonstration a mechanical marvel which ras the result of years of study, hardship and ingenuity on the part of an inventor assisted by mechanical experts whose experience qualified them to carry out the plans of the inventor. The result of years of painstaking effort, trials and disappointments, costly experiments and the expenditure of thousands of dollars could all be shown in a few moments. A few minutes demonstration does not, in this particular case, mean that these men, whe were authorities in their fields, understoo all they saw. What they beheld in actual operation was almost incredible. Although they were prepared in advance to see certain results accomplished, they could not grasp in less than an hour the details of a principle that will radically affect methods of mechanical accounting.

When these men met at the appointed hour and place, a walting taxicab whirled them to a section of the west side of New York, which was totally unfamilia to them. Arriving before a large loft building, the guide led the little party to a machine which accomplished what was heretofore possible only by human intelligence.

That machine performed the remarkable feat of recording approximately eleven entries of a single transaction-eleven entries which would ordinarily have to be made with a pen with eleven chances of making a mistake. In recording a sale, the amount is entered upon a sales check, to be entered upon a bill, agaln upon the segregated sales record, again into the sales ledger, through another operation placed to the credit of the sales person, then to some department, in addition to a record as to whether the package wass dellvered by mail, carried away or sent by regular delivery or express. Instead of this constant juggling with the same figures through a maze of operation with the same figures through a maze of operations
there will be an original entry upon a punched cart. there will be an original entry upon a punched card,
and this card will, through the medium of motor-driven and this card will, through the medium of motor-driven
machines, be automatically sorted into various dirisions and subdivisions, and recorded item by item ulnol counters or wheel sets into adding mechanisms.

Prediction of the Mechanical Ledger.

The ledger cards for the $A$ and $B$ ledger will be placed into a machine, the current will lie turned on, and with the sales checks in the magazine, the machine and with the sales checks in the magazine, the machine the magazine pick out the sales check of Mrs. Aaron and will debit the account with 13.73 , and at the same time add the amount into the total register. After the ledger postings are complete, the sales checks will be passed through the machine again and listed according to departments. When the department totals are secured, the sales checks will be sorted and listed ac. cording to sales persons. At the completion of each sorting, the machine will automatically throw a lever and start the printing mechanism, which will deliver to the operator a printed adding machine list showing the items according to the desired segregations. As the checks are received in payment or part payment of accounts, the entry will be punched upon a card, the ledger sheets will again be returned to the mit chine, and in red upon the ledger sheets will be printed the credits. Automatically the amount paid on account will be sulvtracted from the debit, and the balance, or amount remaining unpaid, will also be printed upon the ledger sheet.

The same principle will be applied to pay rolls; in other words, the laborious ac counting of to-day, the repeated juggling of the same figures into the various combinations necessary to analyye business scientifically, is to become a thing of the past.

If firms could eliminate half of the expense in their accounting departments, losses would be turned into profits and companies who have never paid a dividend, and those who have failed to pay ordinary dividends, would immediately be classed among the successful dividendearning companies.
An understanding of the principles described will convey to the reader something of what these four men saw in operation. They saw entries of sales placed upon cards half the size of an ordinary playing-card. They saw when the entries were typed that underdhe amount sold. Then, as a grand finule, the machinery clicked, a number of levers arose, and there was printed one grand total Showing all amounts which had been segregated to the various departments, all grouped into one grand tota Principle.

There is possinciple. cation of the Jacquard principle, and incation of the Jacquard principle, and in-
ventors will no doubt get to work to apply the same principle to addressing machines. An ordinary card index will be used. The name of John Jones, 201 Broadway, New York City, will be written upon a 3 by 5 card, while underneath the name and address will appear numerous perforations. The cards will be very inexpensive and can be utilized for follow-up or for regular customers, pay roll, etc., and no expensive machinery will be needed to make up new stencils.

There is nothing but common sense in all this. 'To illustrate: Some four thousand years ago, a method of laying bricks came into practice, and this same method was handed down from generation to genwas handed down from generation to gen-
eration until very recently. Now, a disederick Taylor-Gilbreth-has changed the eath the tigures were small round holes. 'l'he numwer of the department, customer's number, clerk's number, amount of sale, and other details, according to requirements, were entered upon these small cards. A thousand cards were placed into the magazine of the machine and the current turned on. The machine itself was one lundred adding machines worked into an integral whole. A part of the mechanism was one hun-

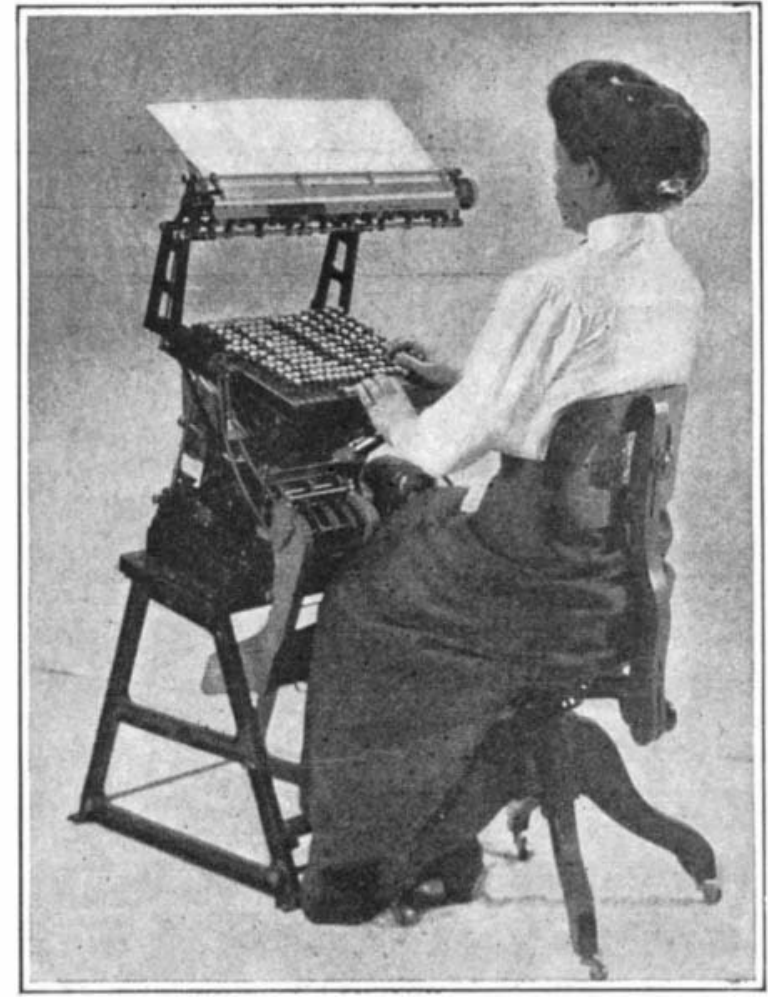

A machine in use by the Census Bureau.

dred wheel sets, upon which were being accumulated these various amounts. If the machine picked up a card for Department 12, whatever amount had been punched upon this card was properly recorded upon wheel set 12

When the machine finished sorting all the cards a lever was thrown, and automatically a printed strip appeared which was identical in appearance with the printed strip secured from a listing adding machine. The printed strip gave the results of
I lepartments $1,2,3$, etc., un to 100 , and oplosite each

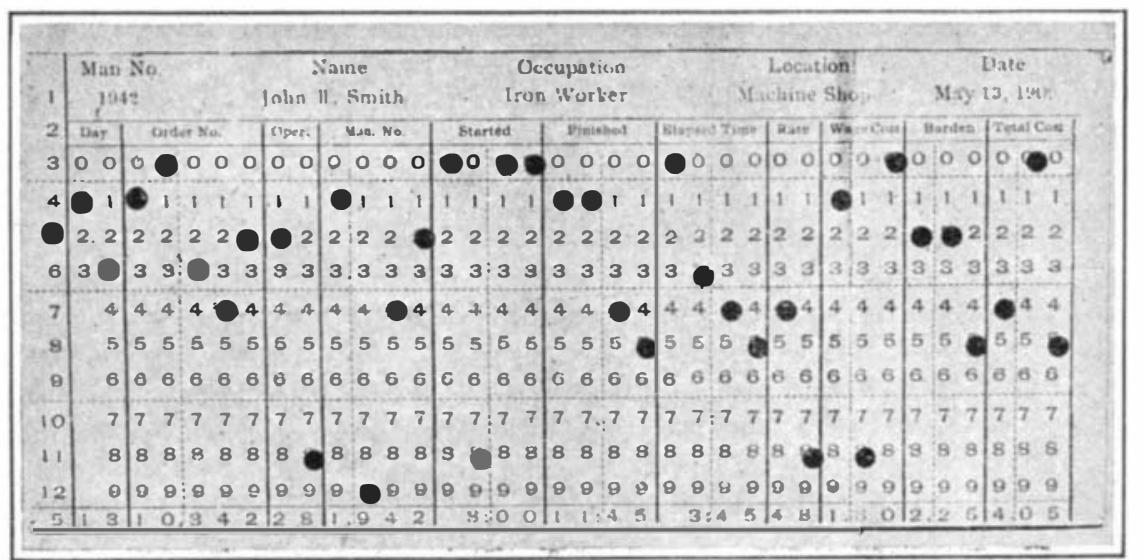

The punched card principle applied to the keeping of a mechanic's account This card has only to be run through a machine in order to obtain a printed statement of the man's output, time, and wage. ciple of Frederick Taylor-Gilbreth-has changed the
general order of things and reduced the number of general order of things and reduced the number of

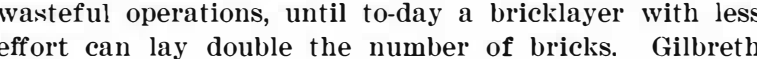
did not discover any new principle. He simply applied common sense to a well-known principle and applied it mortar and bricks instead of tools and steel.

In almost every business house in the country some parallel case can be brought to light by an efficiency engineer when making his examination.

It is common to find a business firm applying efficiency to the order, requisition and billing while totally ignoring the same principles which could be applied to their voucher system with equal results in saring of time and expense. On the other hand, a department store with appliances and systems of various kinds will retain in its purchasing. department an antiquated method for requisitions, simply through failing to see that the same ideas used so effectively in other directions are really a principle which, when combined with it little common sense, go far toward reducing friction and promoting efficiency.

The Pneumatic Typewriter

Now an inventor is working upon a principle where phometic sounds can be recorded upon strips of paper. A man, for example, will call in his stenotypist, who will have this small device instead of the old-fashioned note book and pencil. The little device will be phonetic writer which will punch little holes in strip of paper. 'These strips of paper will be fed into an automatic typewriter, which will typewrite th words as the punchings in the strip will bring into play certain calrds which will allow the machlne to write the lroper combinations.

Thirty years ago business houses had copyists who linboriously wrote pen-written letters, but to-day th stenowrapher fills the place. Twenty years from now hookkeepers, as they are known to-day, will be as great a curiosity as copyists are. In their place will be entry clerks of known ability, and accountants who will take the machine-produced figures, and through the medium of graphic charts, will present to the heads of departments a record of the previous day's business with comparative records by weeks, months and previous years. By ten o'clock each morning the record ing with vital totals will be placed upon the dhe officials, who will then be in a position to keep) their fingers upon the pulse of the business at all times.

There was a time, only fifty years ago, when a large majority of small businesses were run on the cas (ther and hip-pocket principle. Conditions improved; the business men wanted a balance struck off at the end of the year. It was followed by the semi-annual inventory. after which the more progressive wanted a balance sheet every month.

Finally came the weekly report, while in some offices the daily report has arrived. But with increased competition. improved machinery and a reduction i orerhead expense, and through the introduction of efticiency, the average business man, instead of delving into ancient history, a month old, will be able, after reading the latest quotations in the morning paper, to pick up his own balance sheet and know the latest quotation that his husiness has placed upon his ability. With mechanical ledgers somewhat $r$ sembling telephone switchboards, bank clerlis will punch cards as deposits are re ceived or withdrawn. 
Tests of German Aeronautic Motors

$\mathrm{O}_{\mathrm{F}}$ the forty-five representative German aeronautical motors which were entered in the competitio for the 50,000 mark prize offered by the Kaiser for the motor which should make the best showing in a series of tests conducted by the German government, which competition was held on the Kaiser's birthday, innuary 27th, 1913, but nineteen lasted through the eries of tests. Of the nineteen, the best showing was made by the Benz motor-a four-cylinder creation rated at 100 horse-power-designed by Chief Enginee Berger, and it emerged from the contest with a tally of 355 points against 370 which were chalked up for poor performance against the nearest competitor. The other four prizes offered-30,000 marks by the chancellor, 25,000 marks by the minister of war, and 10,000 marks each by the secretary of the navy and the secretary of the interior-were awarded to the makers of the 90 horse-power Daimler, 95 horse-powe N. A. G., 72 horse-power Daimler and 70 horse-power Argus, respectively. The scores of these four contenders were $370,402,406$ and 450 points, respectively.

The conditions imposed and the tests to which the motors were subjected were calculated to compare the motors with regard to their all-around efficiency for the service at hand, and to this end one of the conditions was that the entire motor must be assembled on the spot within a time limit of three days; one of the tests necessitated that the motor be sufficiently light 10) permit the plane in which it was mounted to coast or glide with the motor at a standstill for 15 minutes fter the plane had been elevated for an equal interval, the elevating plane being fifteen per cent. In full the lests were: After erection within the three-day time limit, the motors were subjected to a half-hour preliminary test, running under full load on the block.

Mounted in an aeroplane, the motor was run under full load for fifteen minutes and the plane guided so that it mounted a fifteen per cent grade; the motor then was stopped and the plane guided to earth, it being necessary for it to glide for fifteen minutes.

The motor was then run for seven hours without stollying.

The plane was then driven in horizontal flight for three hours, and after a stop of not half an hour, another two and one half hour flight was indulged in.

The final test consisted in running the motor at top poed for half an hour.

The prize winning motor was possessed of four indiidually cast cylinders with overhead valves; bore and troke were 130 and 180 millimeters, respectively, and the power developed was, as before stated, 100 horsepower at 1,250 revolutions a minute. When speeded up so that the crankshaft speed was 1,380 revolutions a minute, the power was correspondingly greater. In the design of the motor no efforts have been spared to the design of the motor no efforts have been spared to not only of the ignition system (two separate and distinct magnetos operating on separate plugs positioned In oplosite sides of the cylinders were employed), but of the water circulating pump and the oil circulating pump as well.

By way of reducing the weight to the very last degree, the cylinders are formed of a special iron alloy, more easily worked than steel, and at the same time more durable under the conditions. The cylinder more durable under the conditions. The cylinder jackets are of pressed steel and are sweated into place.
During the tests the gasoline consumption was but 210 grammes per horse-power hour, considerably less than that required for the operation of the average automobile motor. This showing is due in part to the arrangement of the intake manifold which is triple branched and innocent of sharp bends calculated to occasion banking of the mixture, and in part to the peculiar construction and location of the carbureter. The latter, or at least the larger portion of the latter is cast integral with the crankcase so that it is in reality a part of the motor and not an appendage. The location has much in its favor, since it not only economizes room and permits of a very compact construction, but also eliminates projecting parts to 3 greater or lesser degree and provides a support for what would otherwise be a free end of the manifold, tend ing to eliminate vibration and strain on the manifold ing to eliminate vibration and strain on the manifold
wolts. Moreover, as the air inlet leads from the inside of the crankcase, the air supplied is heated so that a more homogeneous mixture is obtained. Air is admitted to the crank chamber through a valve provided with a lrotective screen

Circulation of the cooling water is induced by a generously proportioned centrifugal pump driven from the cam-shaft. A second pump of similar construction is jrovided for emergency use, and is driven by means of bevel gears from the magneto drive shaft. Careful balancing of all of the component parts, both statically and dynamically, has resulted in the production of a motor which is singularly free from vibration at al speeds. The weight of the motor, including all piping and fittings is but 153 kilogrammes.

\section{Wind-rolled Snowballs}

' $\mathrm{NE}$ of the strangest pranks of wind and snow was witnessed by residents of Davenport, Washington, the afternoon of January 17th, when a strong gust of wind from the southeast blowing for a period of a minute and a half rolled thousands of snowballs from a particle of snow to big ones large as ordinary barrels and resembling in every respect huge rolls of cotton batting. A peculiarity of the unheard-of prank of nature was the fact that nearly all the rolling was up hill, every south slope for miles being covered with the balls. An inch of snow of the right consistency

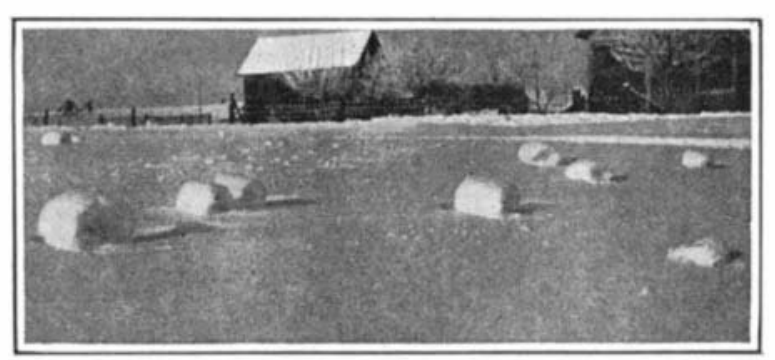

A group of snowballs rolled by the wind.

had fallen on a hard crust of snow and made possible this peculiar phenomenon." The photographs and this brief description were supplied by Edward H. Page of Davenport, Washington.

By an odd coincidence a similar freak has just been reported to the Editor by T. J. Moon of Middletown, N. Y. He writes :

"At the town of Potsdam, N. Y., on the 29th of last December, occurred a light, but very sticky fall of right angles to side of which were found the snowballs which are seen

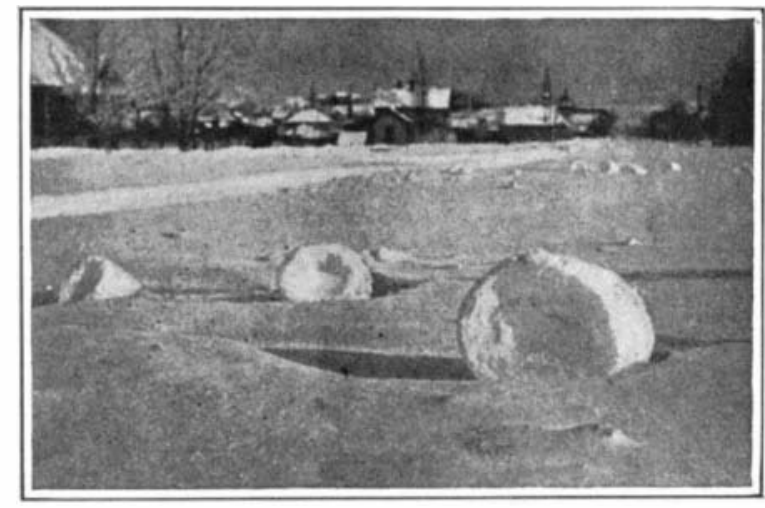

View showing the concave ends of the balls.

in the pictures. The wind had evidently picked up a wisp of snow, rolled it along, as a boy does, to make a snow man, and as they rolled, the size of some reached diameter of over two feet; the concentric layers of added snow could be easily seen, in fact, they show in the print of one taken at close range, also the trail left as the snow picked up, is plainly visible. There were over fifty of these wind-rolled snowballs in our yard alone, and a few near by, where conditions were similar, but in all the experience of the 'oldest inhabitant'

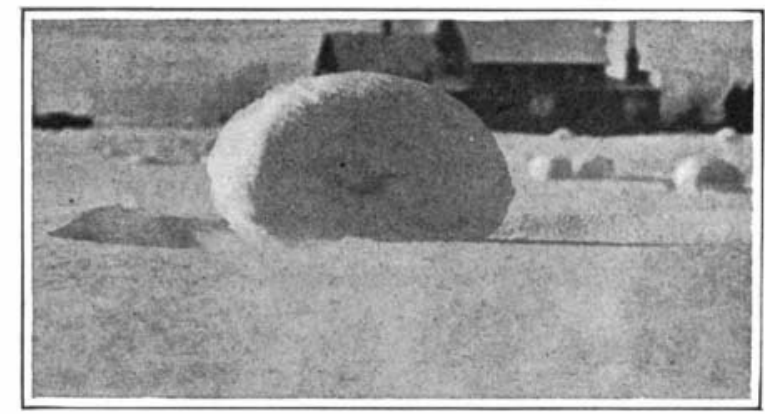

A nearer view of one of the balls.

no such peculiar occurrence had transpired before, and I have never heard of the like, so thought it might be of interest. A peculiar fact was that the rolls of snow were concave at the ends, like the vertebra of a fish, showing the size of the small bit of snow first picked up at the crest of the hill, and indicating that the increase had been in length as well as diameter."

\section{A New Way of Studying Soils}

" $\mathrm{N}$ O industry is so vital to the well-being of a agriculture as the soil. From its treasury it has been estimated that we drew during the year 1909 more than $\$ 8,296,000,000$, and its possibilities are as yet only partially realized. There are still in this country millions of acres which have never felt the plow, while those which are now under cultivation can, by the application of scientific principles, be made to produce many times the present value of their products. How to use and not abuse this great resource is the most important problem which faces the farmer of to-day-one worthy of the best efforts of our most profound and learned scientists; for upon its solution depends the future prosperity of the nation."

This statement from Bulletin 85 of the Bureau of Soils relating to the soils of the country. While a comparatively small percentage of the soils of the United States have been surveyed and analyzed by the department, more than 800 types of soils have been discovered during the progress of the soil survey. The existence of such a large variety of soil types, each possessed of definite and peculiar characteristics, calls possessed of definite and peculiar characteristics, calls soils and their relation to agriculture. The Bulletin says :

"The old idea of soil investigation was to collect samples, examine them in the laboratory, and see what differences could there be determined; the newer idea is to study the characteristics and properties of soils in the field, classify them according to obvious differences, and, with this information in hand, use the laboratory as a means of ascertaining the cause of such variations as cannot be determined in the field. This method of attacking soil problems is the reverse of the usual practice, but because of the great difficulty in duplicating field conditions, it is believed that a field examination should precede laboratory studies. The field observations can thus be used as a check upon laboratory investigation, and as an aid in their interpretation. Field studies furnish a safe and necessary anchor with which to keep the laboratory experimenter from being dashed against the rock of pure speculation. The classifying and mapping of the various soil types, together with the study of the conditions and processes under which they have been formed, will furnish essential and invaluable data for the conduct of laboratory investigations. Nature's great laboratory is in the field, and a study of her methods cannot fail to offer many valuable suggestions, and, in some cases, is the only means of solving her problems. It is through a combination of field and laboratory investigations that an understanding of this extremely complex body - the soil—can be reached."

The Bulletin treats exhaustively of the soils, their origin, formation and best treatment for agricultural purposes, the great difference between the many types, and adds :

"Since the soil varies so much as regards both its inorganic and organic constituents, marked differences in character must necessarily result from the almost indefinite number of combinations which may be found. All these differences, however, may be traced to two sets of factors: First, the character of the rock or material from which the soil has been derived; and, second, the processes or agencies by means of which this material has been changed from mere rock or rock debris into a medium suitable for the growth of plants. The former has to do with soil-forming material, the latter with soil-forming agencies. To these two groups of factors are to be attributed the numerous variations in soil conditions found over various parts of the earth.

"The importance of distinguishing between these two groups of factors cannot be too strongly emphasized. The tendency in the past has been to stress the former to the neglect of the latter, and this has resulted in classifying together soils of very dissimilar character, simply because they were derived from the same rocks or from rocks which have been formed in the same manner."

\section{The Current Supplement}

I this weel's issue of the Scientific A merican SupI PLEMENT Prof. W. E. Plummer speaks in the highest terms of the valuable contributions to knowledge which have been made by amateur astronomers.-Prof. Joly, in a most interesting article, tells us how nuclei of radio-active material have in the course of long geological ages produced halos in the rock containing them, by the emission of disintegration products. These halos are of perfectly definite dimensions, and display many remarkable features. They have, moreover, a definite bearing on the moot question of the age of the earth-Dames Pattison, in an illustrated article, tells us of the life buoys and light ships of New York harbor.-Dr. Ferranti, in delivering his James Watt lecture on the subject of Prime Movers, made some remarkable comments on the scope and limitations of the Diesel engine. This lecture is reproduced in the current issue.-Within easy access from New York city some remarkable features of the new water supply system are being worked out at the Kensico reservoir. These are described in an illustrated article.-E. $\mathbf{N}$. da Andrade reports on the latest vacuum pumps, which far exceed earlier forms in the low pressures attain able.-Dr. H. I. Hollingworth writes on Experimenta I'sychology in its relation to medicine. 